\title{
Penerapan Aplikasi Bantu KKOP Bandara Udara Buntukunik di Kabupaten Tana Toraja
}

\author{
Eko Hadi Purwanto*, Ritzkal \\ Program Studi Teknik Informatika, Universitas Ibn Khaldun Bogor, Indonesia \\ *e-mail koresponden: ehpurwa@uika-bogor.ac.id
}

\begin{abstract}
Abstrak
Kabupaten Tana Toraja sebagai Kawasan Strategis Nasional diwujudkan berupa Bandara Buntukunik. Uji teknis dilakukan selama tiga bulan mulai Februari 2017 oleh tim Kawasan Keselamatan Operasional Penerbangan (KKOP) Direktorat Jenderal Perhubungan Udara. Informasi pembangunan ini telah diketahui masyarakat luas. Banyak pertanyaan dari masyarakat di Pusat Kegiatan (PK), Pusat Pelayanan (PP), Lembang berikut hinterland-nya di dalam wilayah KKOP, dan wilayah terkait lainnya. Reconnaissance Investigation (RI) menghasilkan Tabel Ibukota. Diperhatikan KKOP dalam wilayah Kabupaten Tana Toraja saja, selanjutnya RI menggunakan aplikasi aplikasi bantu geometri. Hasilnya menambah atribut Zona Ketinggian Bangunan (zKTB) dan Candidate Point ke (cPT_n) pada Tabel Ibukota, berikut Peta Urban, Rural \& Conservation Area (URCA) dan Zona Ketinggian Bangunan URCA. Diharapkan hasil ini bisa menjadi salah satu tinjauan untuk Rencana Tata Bangunan dan Lingkungan (RTBL). Dan setelah kesempatan penelitian saat ini RI dilanjutkan bertahap untuk memenuhi kelengkapan data dan informasi. Agar bisa dilakukan kajian interaksi dan interdependensi sosialsistem dan ekosistem wilayah terkait adanya Banda Buntukunik. Hasil kajian ini berupa pengetahuan yang dikelola pengolahan dan publikasinya dengan aplikasi webgis.
\end{abstract}

Kata kunci: Reconnaissance Investigation, Kawasan Keselamatan Operasi Penerbangan, Tana Toraja, Tabel Ibukota.

\section{Abstract}

one (KKOP). This development information is widely known to the public. Many questions from the community in the Activity Center (PK), Service Center (PP), Lembang and the hinterland within the KKOP area, and other related areas. Reconnaissance Investigation (RI) produced the Capital Table. KKOP is observed in the Tana Toraja Regency region only, then $R I$ uses the geometry auxiliary application application. The results add the Building Height Zone (zKTB) attribute and the Candidate Point to (cPT_n) on the Capital Table, following the Urban, Rural \& Conservation Area (URCA) Map and URCA Building Height Zone. This result is expected to be one of the reviews for the Building and Environmental Management Plan (RTBL). And after the current research opportunity, the Republic of Indonesia continued to gradually complete the data and information. In order to study the interaction and social interdependence of regional systems and ecosystems related to the existence of Banda Buntukunik. The results of this study are in the form of managed knowledge processing and publication with the webgis application. 
Keywords : Reconnaissance Investigation, Aviation Safety Operation Area, Tana Toraja, Tables of the Capital.

\section{PENDAHULUAN}

Pemerintah mengembangkan tiga bandara udara agar membuka kawasan wisata Toraja di Sulawesi Selatan yaitu, Bandara Pontingku dan Bandara Buntukunik di Kabupaten Tana Toraja, serta Bandara Bua di Kabupaten Lawu. Sehingga pengembangan Tata Ruang dan Lingkungan Kabupaten Tana Toraja dan Lawu sebagian terbatas akibat adanya Kawasan Keselamatan Operasional Penerbangan (KKOP), terutama batasan ketinggian dan perletakan bangunan, serta pemakaian alat navigasi tertentu, juga hal yang lain yang dinilai mengganggu penerbangan.

Dalam kesempatan penelitian ini diperhatikan posisi, perletakan dan penjelas atau atribut lainnya yang di butuhkan dalam Reconnaissance Investigation atau Studi Penjajagan di berbagai Pusat Pelayanan atau Ibukota yang terletak di dalam KKOP Bandara Buntukunik.

Penerapan Peraturan KKOP Bandara Buntukunik termasuk dalam wilayah empat kabupaten yaitu Kabupaten Tana Toraja, Kabupaten Tana Toraja Utara, Kabupaten Luwu dan Kabupaten Enrekang [2]. Perubahan fungsi lahan dan prasarana \& sarana akan terjadi akibat penerapan KKOP yaitu salah satunya yang berkenaan dengan batasan ketinggian bangunan. Batasan ketinggian bangunan diperlukan dalam pembuatan Rencana Tata Bangunan dan Lingkungan (RTBL) di empat wilayah kabupaten tersebut, yaitu sebagai materi pembentukan Peta Kawasan Zona Ketinggian Bangunan.

Uji teknis selama tiga bulan mulai Februari 2017 oleh tim Kawasan Keselamatan Operasional Penerbangan (KKOP) Direktorat Jenderal Perhubungan Udara. Namun saat ini, September 2017 belum diterbitkan Peraturan Menteri Perhubungan (Permenhub) terkait KKOP Bandara Buntukunik ini.

Sebelum terbit peraturan tersebut di atas bisa dilakukan Studi Penjajagan pembentukan Zona Tinggi Bangunan, dengan memperhatikan Album Peta Rencana Tata Ruang Kabupaten Tana Toraja 2011-2030, dan KKOP pesawat sejenis [1]. Hasil Studi Penjajagan menambah atribut Zona Ketinggian Bangunan (zKTB) dan Candidate Point ke (cPT_n) pada Tabel Ibukota, berikut Peta Urban, Rural \& Conservation Area (URCA) dan Zona Ketinggian Bangunan URCA. Diharapkan hasil ini bisa menjadi salah satu tinjauan untuk Rencana Tata Bangunan dan Lingkungan (RTBL). Dan RI setelah kesempatan penelitian saat ini dilanjutkan bertahap untuk memenuhi data dan informasi untuk kajian interaksi dan interdependensi sosialsistem dan ekosistem wilayah terkait adanya Banda Buntukunik.

Dikemukakan hipotesa atau perkiraan berbagai hubungan variabel sebagai berikut:

1) Lapisi atau overlay Peta Ketinggian dengan Peta Kelerengan.

2) Perbedaan atau jarak diatas permukaan laut (mdpl) antara permukaan lapisan KKOP dengan pada tiap Candidate Point (mdpl) dalam jarak kontur sebesar 50 meter.

3) Hasil proses nomor satu dan dua digolongkakan dalam zonasi berdasarkan ketinggian bangunan.

4) Penempatan klasifikasi ketinggian bangunan pada urban area atau rural area, atau conservation area

5) Menyusun Candidate Point dengan penamaan cPT_n yaitu $\mathrm{cPT}$ 1, dan seterusnya di Pusat Pelayanan dalam KKOP

6) Melengkapi Tabel Ibukota dengan atribut Zona Ketinggian Bangunan (zKTB) dan Candidate Point (cPT_n)

Penelitian ini di danai oleh LPPM UIKA dengan keluaran yang ditunda atau yang dilakukan pada penelitian Ristekdikti selanjutnya, sebagai berikut: 
1) Keluaran wajib berupa aplikasi webgis yang bermanfaat membantu Reconnaissance Investigation atau Studi Penjajagan sebelum Feasibility Study dalam hal pembaharuan data lapangan. Data awal yang bermanfaat untuk studi sekilas ke lapangan oleh tenaga ahli berpengalaman lebih dari 10 tahun. Agar memperoleh nilai penjajagan apakah satu gagasan atau berbagai gagasan dilanjutkan pada tahap Feasibility Study (FS) atau Study Kelayakan di capai penuh pada tahun 2020. Dan hasil FS untuk bahan kajian interaksi dan interdependensi sosialsistem dan ekosistem wilayah terkait adanya Banda Buntukunik. Data dan pengetahuan diolah dan dipublikasi dengan aplikasi webgis

2) HAKI diajukan pada tahun 2020.

3) Publikasi ilmiah diajukan pada Jurnal Internasional bereputasi (Geo-Spatial Information Science-USA) yang terindeks Scopus tahun 2020, atau Teknologi Informasi.

4) Buku ISBN tentang penyusunan database, pembuatan aplikasi dan manfaat aplikasi ini pada tahun 2021.

Maksud penelitian ini bahwa bisa diperkirakan materi usulan pemebentukan zona ketinggian bangunan berdasarkan data sekunder yang ada pada Album Peta Rencana Tata Ruang Kabupaten Tana Toraja 2011-2030 [4], sehingga pihak terkait bisa memperoleh data dan infomasi draft Kawasan Zona Ketingggian Bangunan di bawah KKOP Banda Buntukunik dalam wilayah Kabupaten Tana Toraja, sembari menunggu Permenhub tentang KKOP Bandara Buntukunik. Tujuan penelitian ini diharapkan memperoleh data dan infomasi sebagai berikut:

1. Pendataan seluruh Ibukota di dalam KKOP Bandara Buntukunik.

2. Pendataan posisi Ibukota pada zonasi kelerengan yang termasuk urban area atau rural area, atau conservation area.

3. Penambahan atribut Zona Ketinggian Bangunan (zKTB), Tipe Area dan Candidate Point (cPT_n) pada Tabel Ibukota.

\section{METODE PENELITIAN}

Metode Pelaksanaan Penelitian Pelaksanaan penelitian menggunakan aplikasi bantu design dan drafting seperti pada langkah-langkah pada Gambar.1.

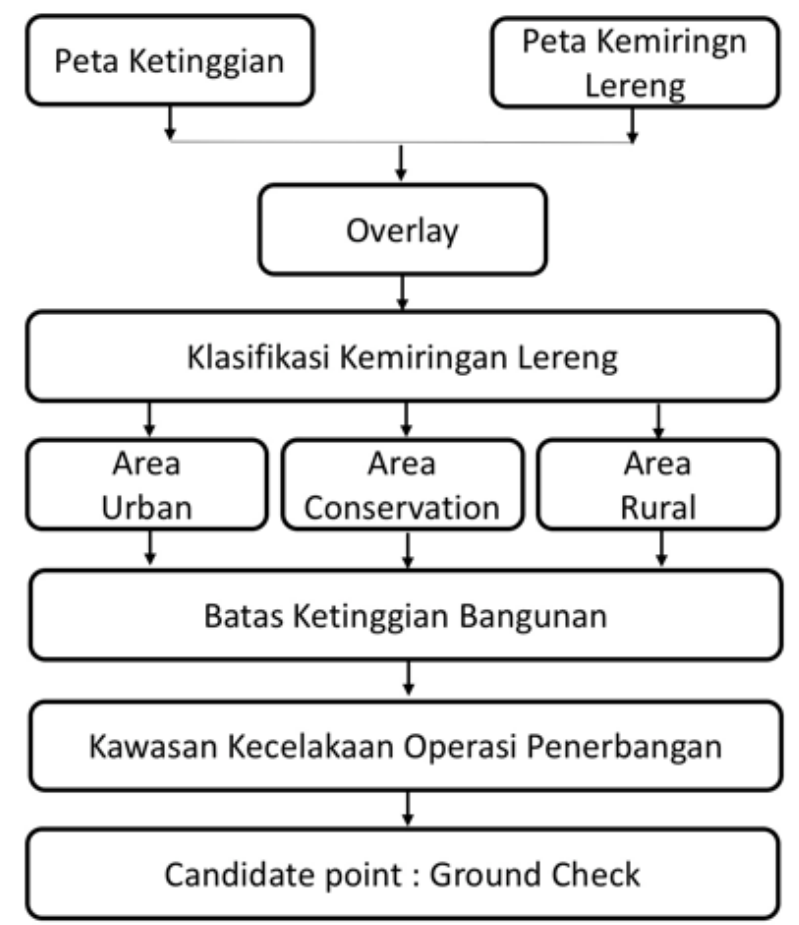




\section{Gambar 1. Metode Pelaksanaan Penelitian}

Metode Pelaksanaan Penelitian terdiri tujuh langkah dengan 10 bagan. Peta Ketinggian dan Peta Kemiringan Lereng diperoleh dari Album Peta Rencana Tata Ruang Kabupaten Tana Toraja 2011-2030. Diharapkan keluaran berupa Draft Kuesioner untuk Ground Check.

\section{a. Peta Ketinggian}

Peta Ketinggian diperhatikan sebagai salah satu peryaratan persyaratan fungsi lahan seperti pada Gambar 2.

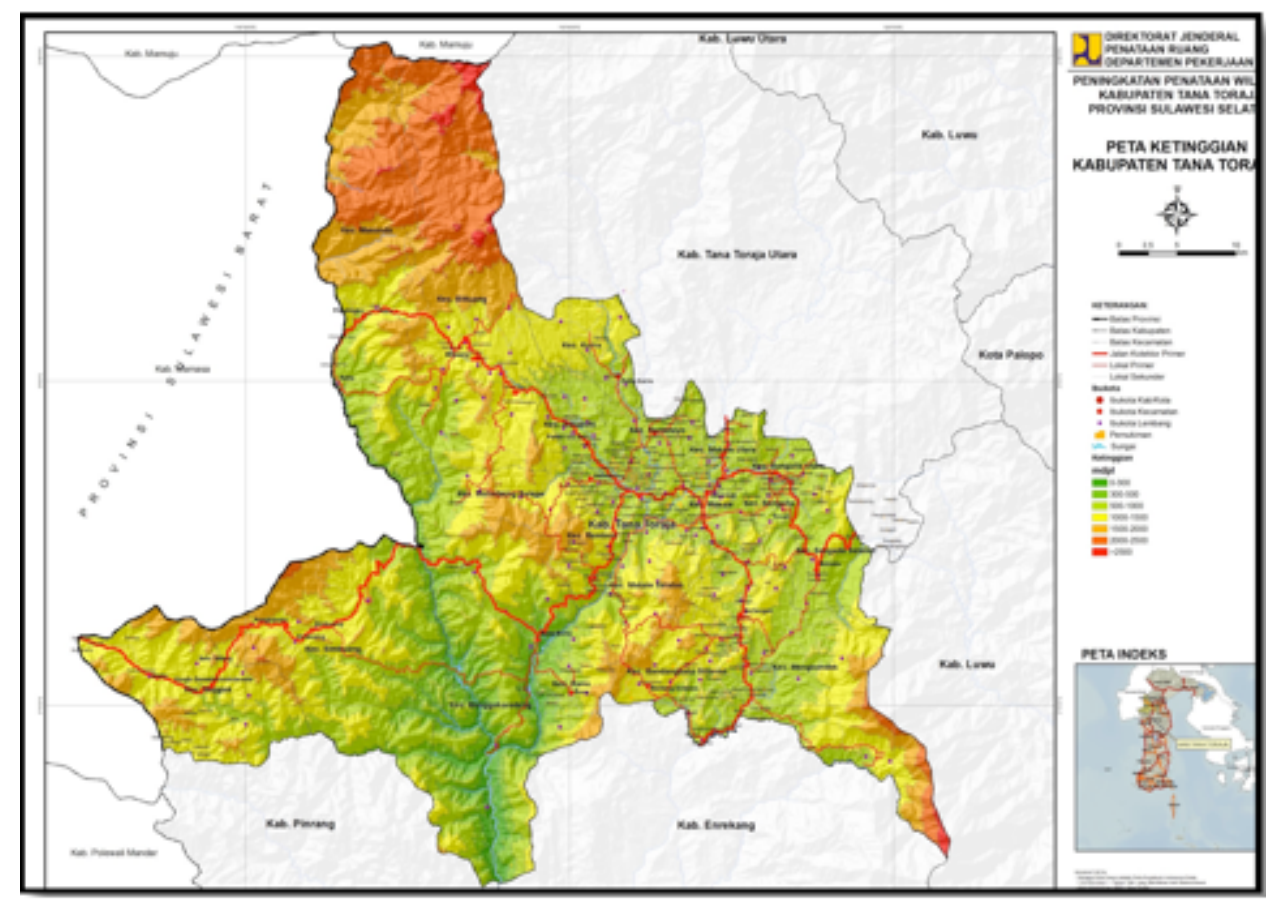

Gambar 2. Peta Ketinggian

\section{b. Peta Kemiringan Lereng}

Peta Kemiringan Lereng diperhatikan sebagai salah satu persyaratan fungsi lahan seperti pada Gambar 3. 


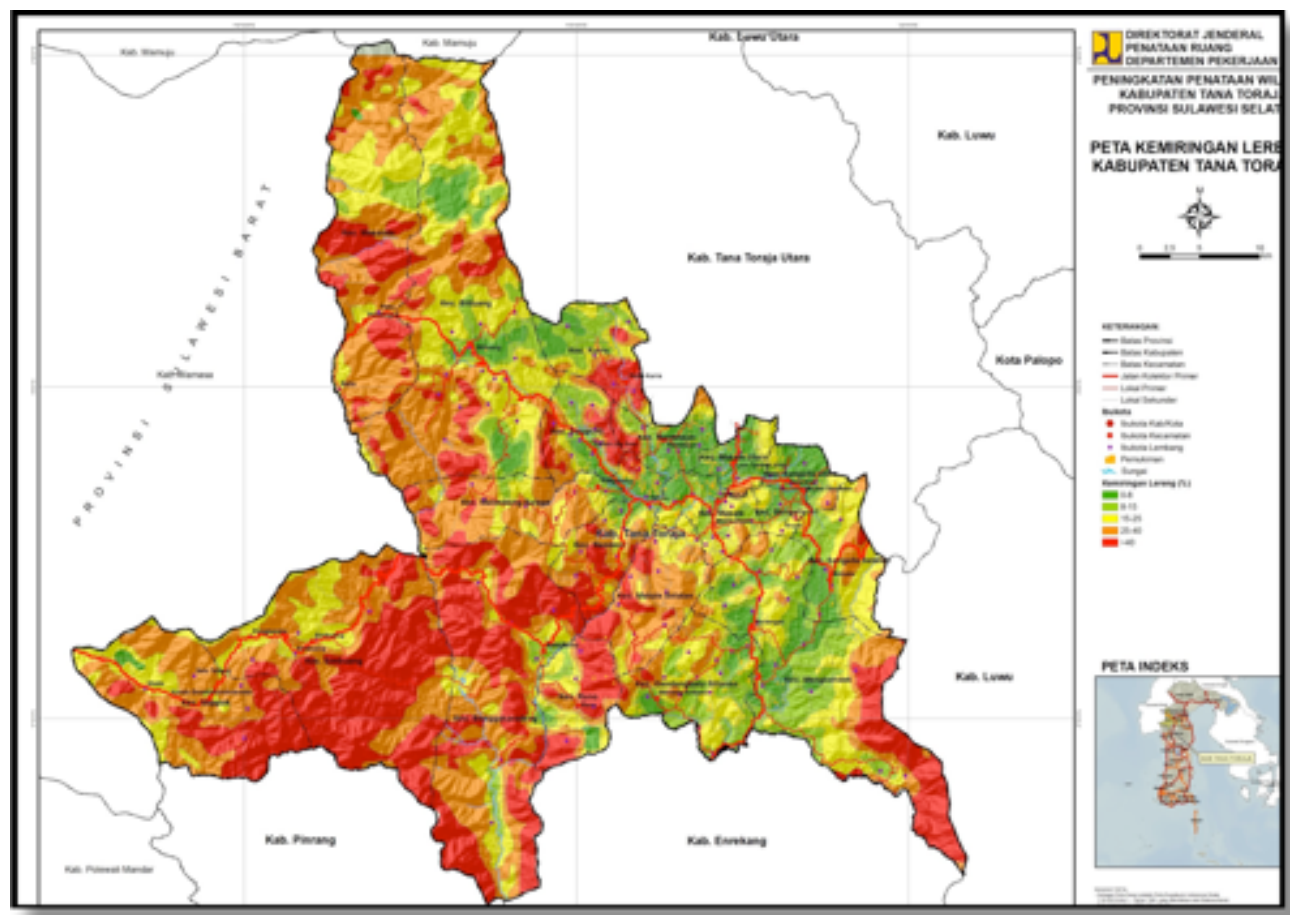

Gambar 3. Peta Kemiringan Lereng

\section{c. Overlay Peta Ketinggian dengan Peta Kemiringan Lereng}

Lapisi atau overlay Peta Ketinggian dengan Peta Kelerengan agar diperoleh klasifikasi kelerengan yang termasuk urban area atau rural area, atau conservation area.

\section{d. Klasifikasi Kemiringan Lereng}

Klasifikasi kemiringan kelerengan yang termasuk urban area atau rural area, atau conservation area di bawah KKOP menurut 3.4.3 diperuntukan untuk Urban Area, Rural Area dan Conservartion Area sebagai berikut:

1. Urban Area dengan kemiringan lereng 0-8 dan 8-15

2. Rural Area dengan kemiringan lereng 0-8, 8-15, 15-25 dan 25-40

3. Conservartion Area dengan kemiringan lereng $>40$

Dan kemudian diterapkan data ketinggian bangunan dengan memperhatikan nilai jarak dalam meter antar permukaan lapisan KKOP dengan permukaaan urban area atau rural area, atau area konservasi. Berikut klasifikasi kelerengan.

\section{e. Area Urban, Area Rural \& Conservation Area}

Diperhatikan perolehan penempatan hasil overlay sebagai dasar penentuan zonasi ketinggian bangunan.

\section{f. Materi Batasan Ketinggian Bangunan}

Usulan materi zona ketinggian bangunan ditingkat studinya dengan bentukan tiga dimensi.

\section{g. Candidate Point : Ground Check}

Candidate Point disusulkan sebagai bahan untuk melakukan Ground Check ke lapangan. Jika ada kemudahan perolehan data Jaring Patok Utama Horizontal (JPUH) setempat, maka usulan Candidate Point mengacu ke Patok Utama terdekat. Dan jika sukar 
memperoleh JPUH, maka tiap Candidate Point ditentukan dengan alasan-alasan tertentu.

\section{KAJIAN PUSTAKA}

\section{a. State of The Art}

Menyusun materi RS dimudahkan dengan Geo-Tool dan CAD dengan digitizing on screen memperoleh prototype [1,2], yaitu Tabel Ibukota dengan Record Posisi Pusat Kegiatan Lingkungan, Pusat Kegiatan Lingkungan Promosi, Pusat Pelayanan Kawasan dan Pusat Pelayanan Lingkungan (Lembang). Dan data sementara Tinggi Bangunan.

\section{b. Road Map} berikut:

Penelitian yang dilakukan terkait KKOP Bandar Buntukunik sebelum ini, sebagai

Penggunaan Geo-Tool dengan CAD cukup dilakukan dengan digitizing on screen untuk memperoleh informasi yang ada pada peta tematik [1], akibat penerapan geometri KKOP. Seperti diketahui informasi pokok namun menyeluruh dari RTRW cukup sebagai dasar pertimbangan dalam tahapan Reconnaissance Investigation dan merupakan materi-materi KAK, sehingga inovasi dalam Usulan Teknis/Proposal akan mempertajam gagasan, serta menghindari perubahan lingkup penelitian yang seringkali sulit ditangani dengan seksama.

Perlu adanya koordinasi dan sinergi dalam penyusunan KKOP terutama KKOP dapat melintasi batas wilayah administrasi kabupaten di sekitarnya.

Diperoleh prototype Tabel Ibukota [2], dengan Record Posisi Pusat Kegiatan Lingkungan, Pusat Kegiatan Lingkungan Promosi, Pusat Pelayanan Kawasan dan Pusat Pelayanan Lingkungan (Lembang). Terutama memperoleh data sementara Tinggi Bangunan sebagai hasil penjajagan berdasarkan data sekunder dengan batasan pada posisi dan kisaran nilai ketinggian tertentu yang belum berstatus for construction.

\section{c. Studi Literatur}

Diperhatikan desain record data dengan 12 field yaitu, FID, Shape, ID, Status, Nama, Bujur, Lintang, Elevasi, bidKKOP, btsKKOP, tinggBGN, Kecamatn. Desain diterapkan pada ke empat objek spasial di atas pada Tahap Penjajagan, seperti pada Tabel.2.

Tabel 2. Ibukota

\begin{tabular}{|c|c|c|c|c|c|c|c|c|c|c|c|}
\hline $\begin{array}{l}\text { FI } \\
\text { D }\end{array}$ & $\begin{array}{c}\text { Shap } \\
\text { e }\end{array}$ & $\begin{array}{l}\text { I } \\
\text { d }\end{array}$ & Status & Nama & Bujur & Lintang & $\begin{array}{c}\text { Elev } \\
\text { asi }\end{array}$ & bidKKOP & $\begin{array}{c}\text { Bst } \\
\text { KKO } \\
\text { P }\end{array}$ & $\begin{array}{c}\text { Ting } \\
\text { gi } \\
\text { BGN }\end{array}$ & Kecamatan \\
\hline 1 & $\begin{array}{c}\text { Poin } \\
t\end{array}$ & 3 & $\begin{array}{l}\text { P. Pelayanan } \\
\text { Lingkungan }\end{array}$ & $\begin{array}{l}\text { Rangkaia } \\
\mathrm{n} \text { Tangan }\end{array}$ & $\begin{array}{c}119^{0} 50^{\prime} \\
29,403^{\prime \prime} \\
\text { E }\end{array}$ & $\begin{array}{c}3^{0} 6^{\prime} \\
31,504 ” \\
\text { S }\end{array}$ & 900 & $\begin{array}{c}\text { Kawasan } \\
\text { di bawah } \\
\text { horisontal } \\
\text { luar }\end{array}$ & 950 & 150 & $\begin{array}{l}\text { Mangkend } \\
\text { ek }\end{array}$ \\
\hline 2 & $\begin{array}{c}\text { Poin } \\
t\end{array}$ & 4 & $\begin{array}{l}\text { Pusat } \\
\text { Pelayanan } \\
\text { Kawasan }\end{array}$ & Batualu & $\begin{array}{c}119^{0} 52^{\prime} \\
14,348^{\prime}, \\
\text { E }\end{array}$ & $\begin{array}{c}3^{0} 7^{\prime} \\
29,089^{\prime} \\
\text { S }\end{array}$ & 800 & $\begin{array}{c}\text { Kawasan } \\
\text { di bawah } \\
\text { permukaan } \\
\text { kerucut }\end{array}$ & 860 & 60 & $\begin{array}{l}\text { Sangalla } \\
\text { Selatan }\end{array}$ \\
\hline 3 & $\begin{array}{c}\text { Poin } \\
t\end{array}$ & 2 & $\begin{array}{l}\text { PKL } \\
\text { Promosi }\end{array}$ & $\begin{array}{l}\text { Getenga } \\
\mathrm{n}\end{array}$ & $\begin{array}{c}119^{0} 54^{\prime} \\
29,403^{\prime} \\
\text { E }\end{array}$ & $\begin{array}{c}3^{0} 12^{\prime} \\
31,009^{\prime} \\
\mathrm{S}\end{array}$ & 800 & $\begin{array}{c}\text { Kawasan } \\
\text { di bawah } \\
\text { horisontal } \\
\text { dalam }\end{array}$ & 847 & 47 & $\begin{array}{c}\text { Mangkend } \\
\text { ek }\end{array}$ \\
\hline 0 & $\begin{array}{c}\text { Poin } \\
t\end{array}$ & 1 & $\begin{array}{l}\text { Pusat } \\
\text { Kegiatan } \\
\text { Lingkungan }\end{array}$ & $\begin{array}{l}\text { Ibukota } \\
\text { Kab/kota } \\
(\mathrm{PKL})\end{array}$ & $\begin{array}{c}119^{0} 53^{\prime} \\
14,625^{\prime} \\
E\end{array}$ & $\begin{array}{c}3^{0} 6 \\
33,118^{\prime} \\
\text { S }\end{array}$ & 500 & $\begin{array}{c}\text { Kawasan } \\
\text { di bawah } \\
\text { horisontal } \\
\text { luar }\end{array}$ & 950 & 450 & $\begin{array}{l}\text { Makale } \\
\text { Utara }\end{array}$ \\
\hline
\end{tabular}


Demikianlah hasil penelitian sebelum ini dengan mengamati batas ketinggian bangunan, yang selanjutnya bisa dijadikan contoh mementukan Panduan Tinggi Bangunan di Sekitar Bandara Buntukunik. Keempat tipe Pusat Kegiatan/Pelayanan merupakan entitas yang diakomodasikan dalam desain record data dengan 12 field yaitu, FID, Shape, ID, Status, Nama, Bujur, Lintang, Elevasi, bidKKOP, btsKKOP, tinggBGN, Kecamatan. Desain Tabel tersebut diterapkan pada ke empat objek spasial di atas yang berupa Point [1].

\section{d. Landasan Teori}

\section{Kawasan Kecelakaan Operasi Penerbangan (KKOP)}

Pembagian Kawasan Kecelakaan Operasi Penerbangan (KKOP) yang diterapkan di Bandara Buntu Kunik seperti pada Gambar 4, 5 dan 6.

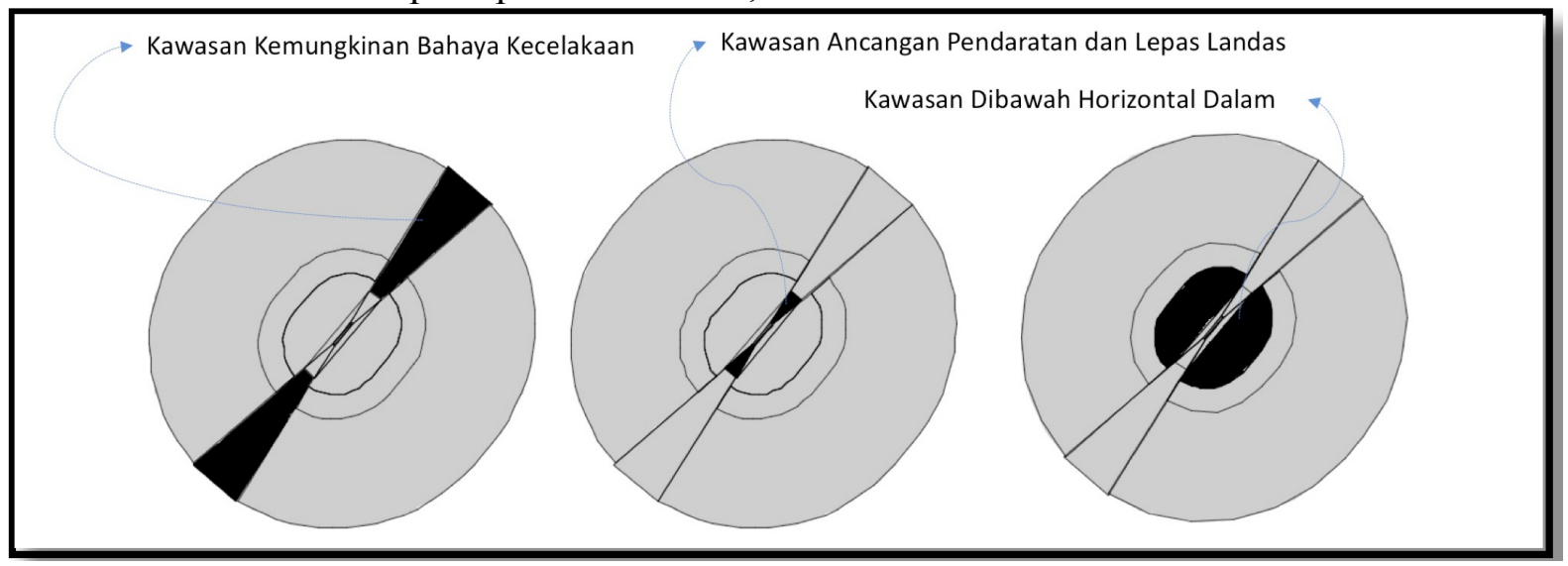

Sumber: Studi Tim RTBL [2]

Gambar 4. Pembagian Kawasan Kecelakaan Operasi Penerbangan (KKOP) -1

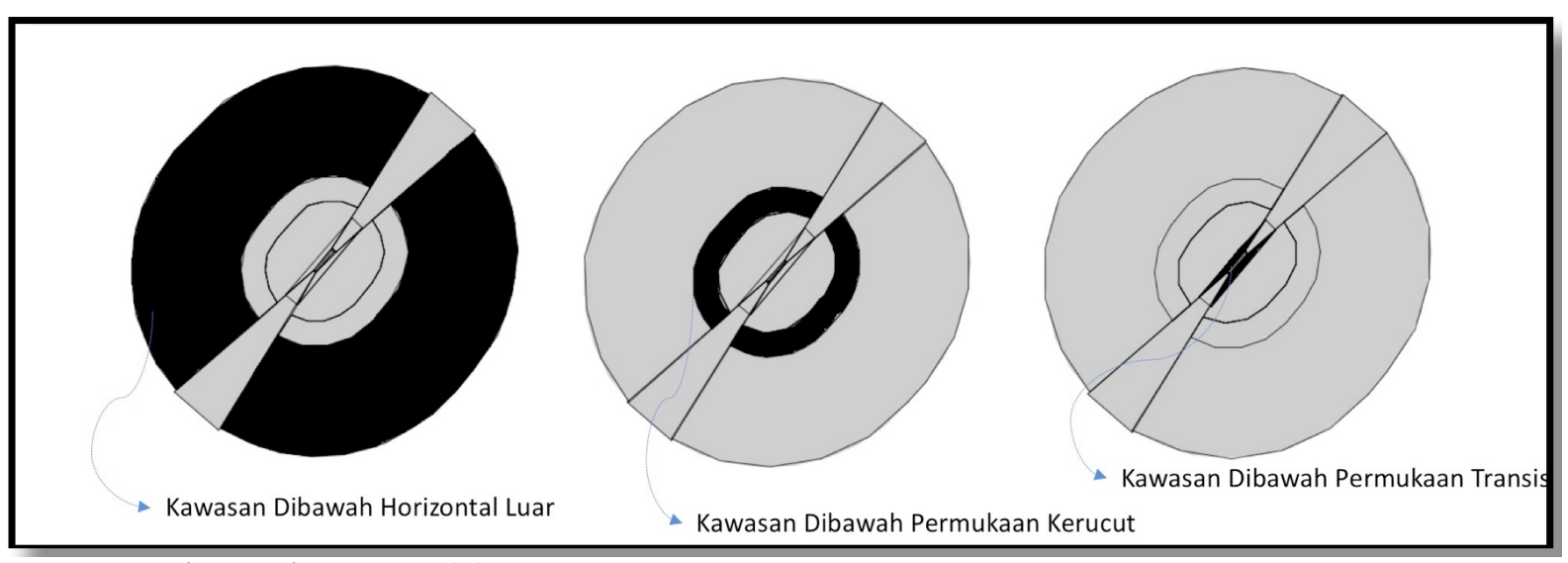

Sumber: Studi Tim RTBL [2]

Gambar 5. Pembagian Kawasan Kecelakaan Operasi Penerbangan (KKOP) - 2 


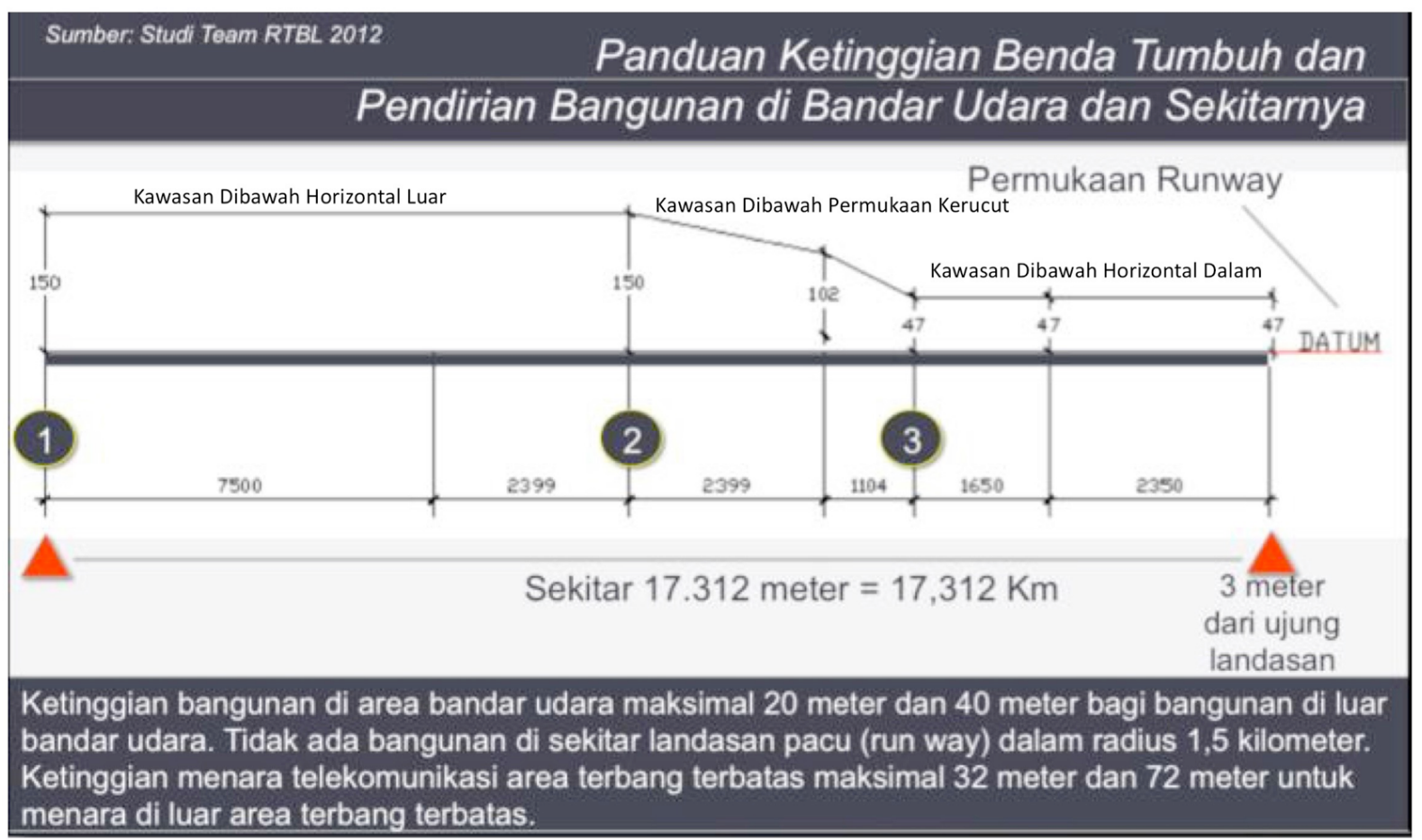

Sumber: Studi Tim RTBL [2]

\section{Gambar 6. Penampang KKOP}

Gambar 4 dan 5 untuk menentukan beda jarak antara batas ketinggian kawasan dengan muka tanah keempat Pusat Kegiatan/Pelayanan. Panduan ketinggian bangunan di hitung dari ketinggian dataran sekitar bandara yaitu $800 \mathrm{dpl}$ ke bidang datar KKOP.

\section{Bangunan}

KKOP pesawat berbadan besar sejenis bisa mengacu pada Keputusan Menteri Perhubungan Nomor: KM.69 Tahun 1998 (KMP 69/1998). Tentang Kawasan Keselamatan Operasi Penerbangan di Sekitar Bandar Udara Selaparang Mataram [9].

Selain ketentuan geometri KKOP juga diperhatikan batas-batas ketinggian bangunan serta benda tumbuh Pasal 1 yaitu;

1) Bangunan adalah suatu benda bergerak maupun tidak bergerak yang bersifat sementara maupun tetap yang didirikan orang atau yang telah ada secara alami, antara lain gedung-gedung, menara mesin derek, cerobong asap, gundukan tanah, jaringan transmisi di atas tanah dan bukit atau gunung.

2) Kawasan Keselamatan Operasi Penerbangan adalah batas-batas kawasan dan batasbatas ketinggian bangunan serta benda tumbuh yang ditentukan untuk Keselamatan Operasi Penerbangan.

3) Tinggi bangunan dalam meter diperoleh yaitu data tinggi bidang KKOP di atas permukaan laut (dpl) dikurangkan dengan elevasi (dpl) permukaan yang bersangkutan.

\section{Klasifikasi Kemiringan Lereng}

Klasifikasi Kemiringan Lereng dengan nilai skor seperti pada Tabel 3. 
Tabel 3. Klasifikasi Kemiringan Lereng

\begin{tabular}{ccc}
\hline KELAS & KEMIRINGAN $(\%)$ & KLASISFIKASI \\
\hline I & $0-8$ & Datar \\
II & $8-15$ & Landai \\
III & $15-25$ & Agak Curam \\
IV & $25-40$ & Curam \\
V & $>40$ & Sangat Curam \\
\hline
\end{tabular}

\section{Candidate Point untuk Ground Check}

Candidate Point disusulkan sebagai bahan untuk melakukan Ground Check ke lapangan pada tahapan penelitian selanjutnya. Jika ada kemudahan perolehan data Jaring Patok Utama Horizontal (JPUH) setempat, maka usulan Candidate Point mengacu ke Patok Utama terdekat. Dan jika sukar memperoleh JPUH, maka tiap Candidate Point ditentukan dengan alasan-alasan tertentu yaitu di pusat Ibukota.

\section{HASIL DAN PEMBAHASAN}

\section{a. Overlay Peta Ketinggian dengan Peta Kemiringan Lereng}

Posisi Peta Ketinggian dan Peta Kemiringan Lereng sebelum dilakukan overlay dengan menyisipkan, disesuaikan besaran serta diposisikan dengan peta yang ada agar terapan KKOP seragam, seperti pada Gambar 7.

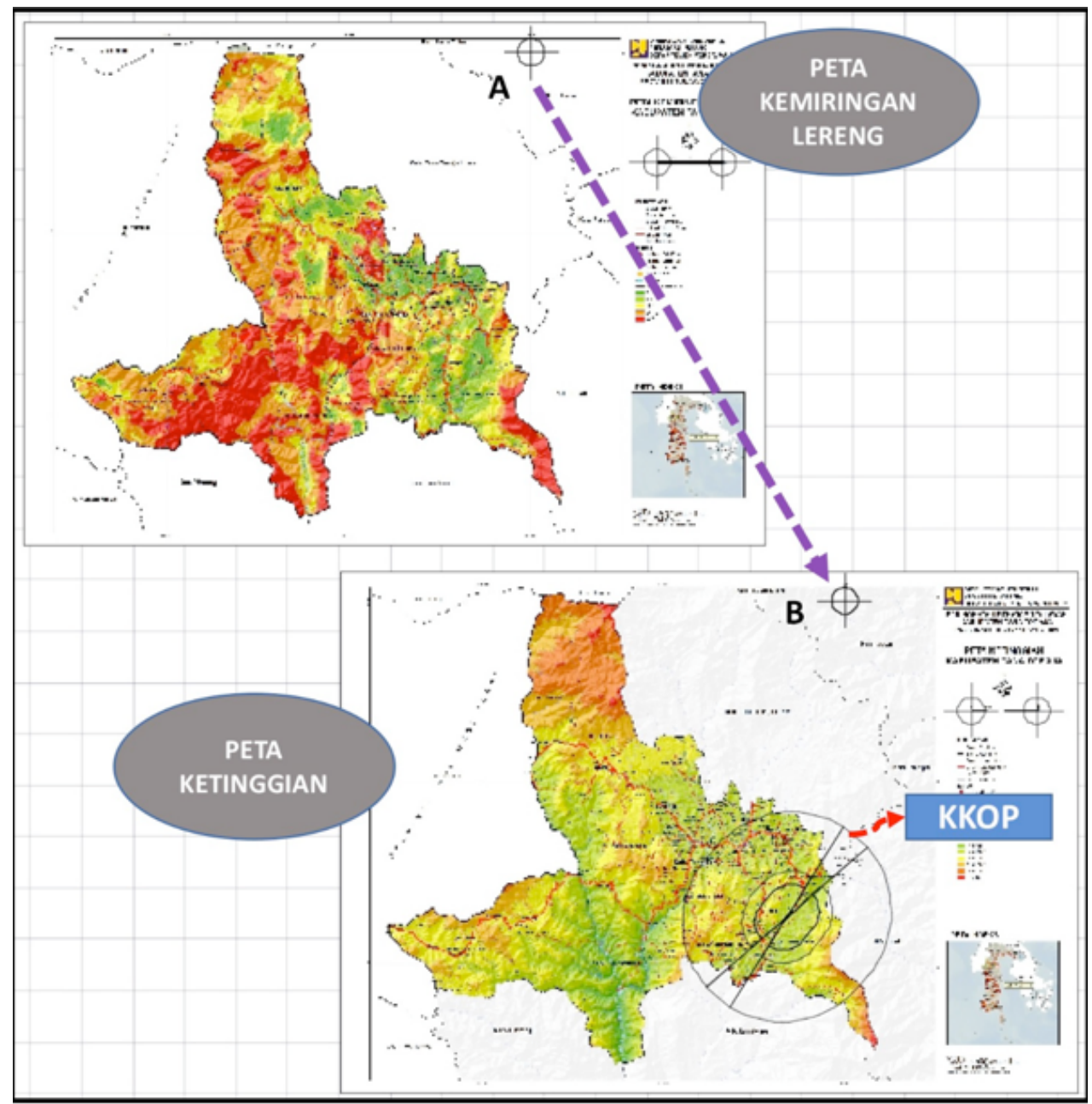

Gambar 7. Sebelum Dilakukan Overlay 
Terapan KKOP pada Peta Kemiringan Lereng seperti pada Gambar 8.

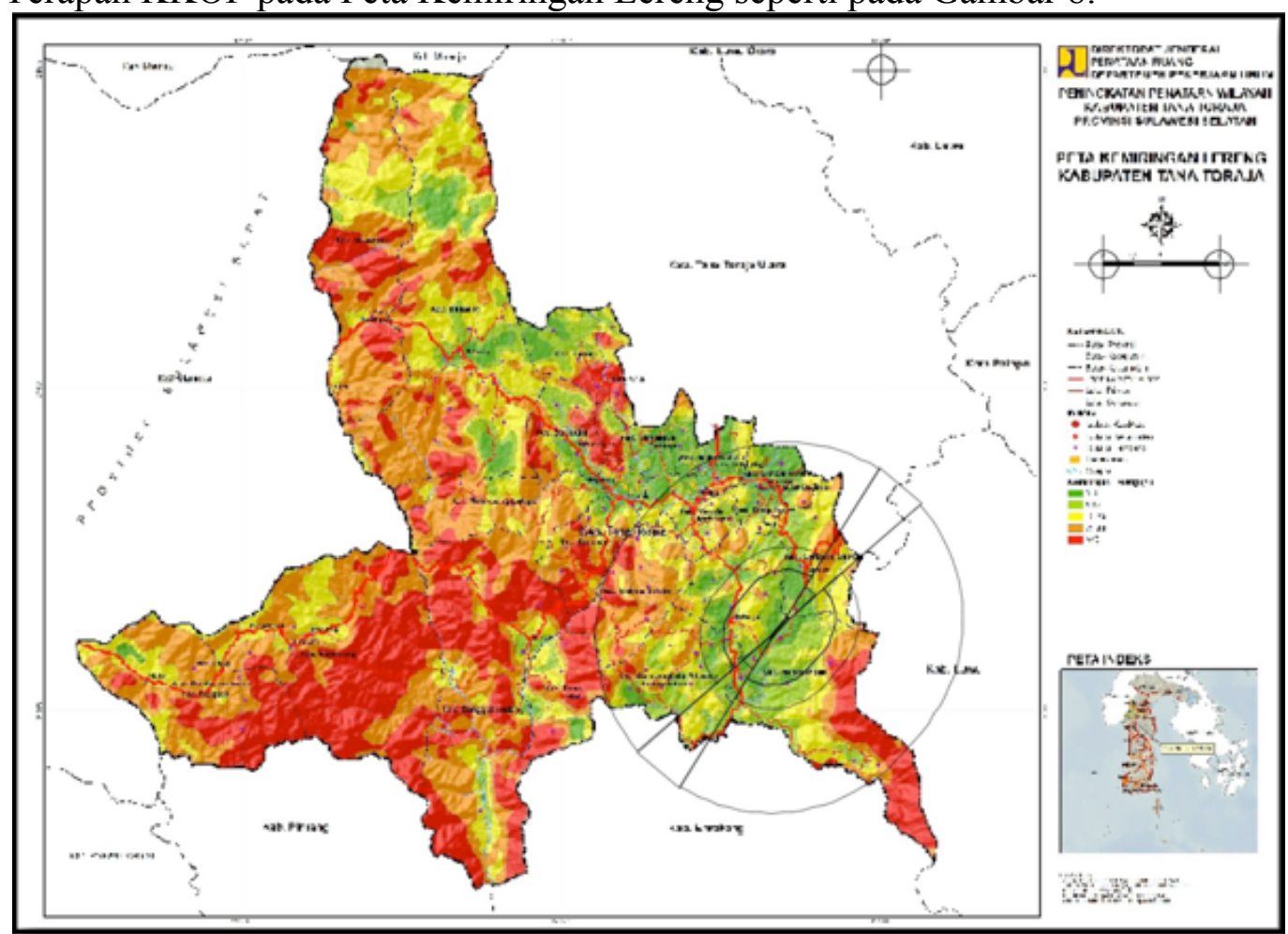

Gambar 8. Hasil Overlay, KKOP pada Peta Kemiringan Lereng

Selain memperoleh lima klasifikasi kemiringan lereng juga posisi Pusat Pelayanan / Ibukota di dalam KKOP, seperti pada Gambar 9.

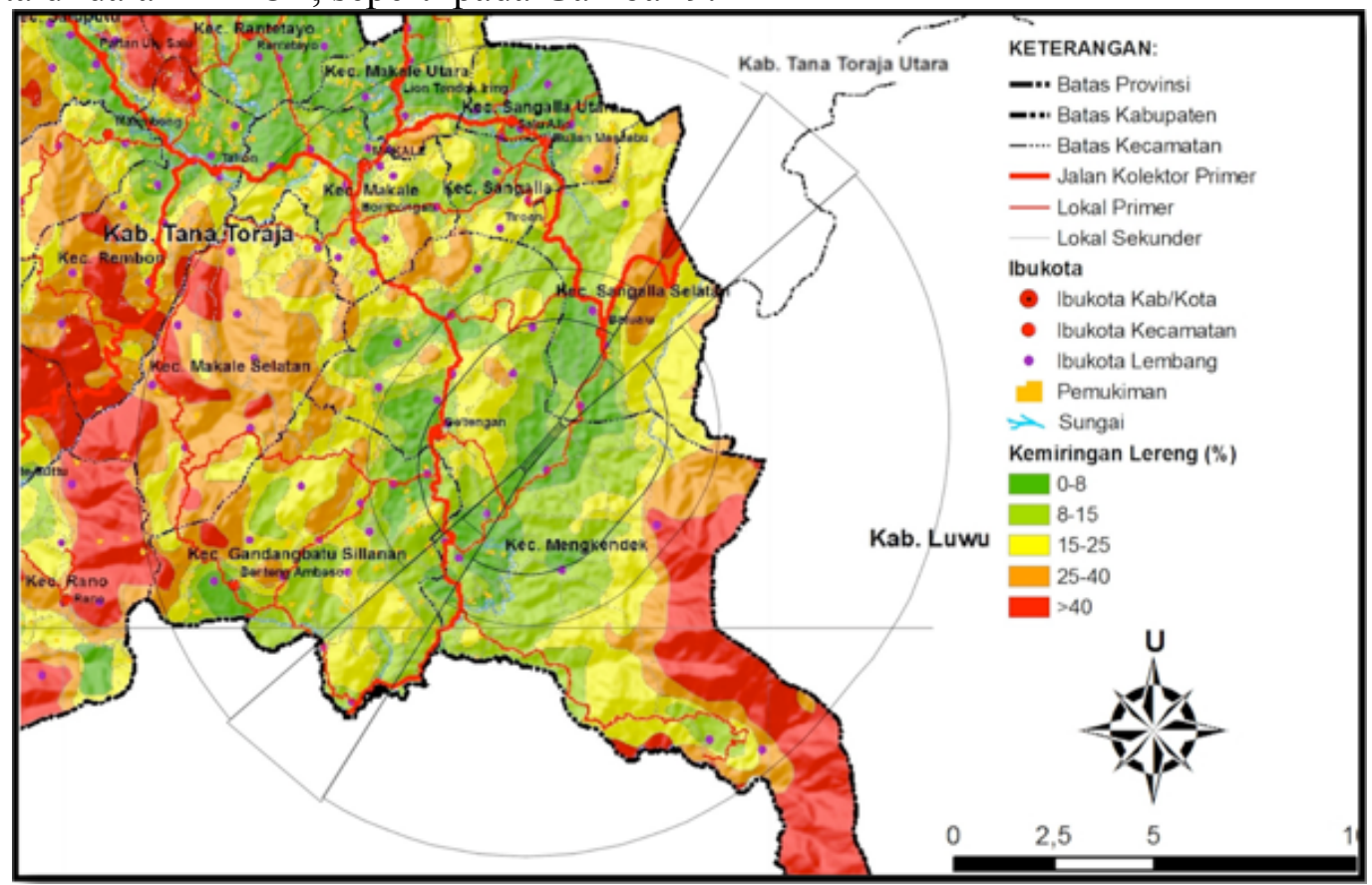

Gambar 9. Ibukota di Bawah KKOP dalam Peta Kemiringan Lereng

\section{b. Pendataan Pusat Pelayanan di dalam KKOP}

Ternyata Ibukota Kecamatan dan Ibukota Lembang yang berada dalam KKOP. Pada kesempatan ini bisa dihitung jumlahnya namun semua nama Ibukota teridentifikasikan pada penelitian selanjutnya. 
Menghitung jumlah Ibukota berikut memberikan kode urut dan juga terdata wilayah administrasinya, maka memerlukan Peta Administrasi dengan menyisipkan, disesuaikan besaran serta diposisikan dengan peta yang ada, ternyata 200 dpi buram di lembar kerja CAD, maka kerapatan pixelnya dinaikan menjadi 300 dpi dengan photo processing, lalu proses diulang dengan hasil seperti pada Gambar 10.

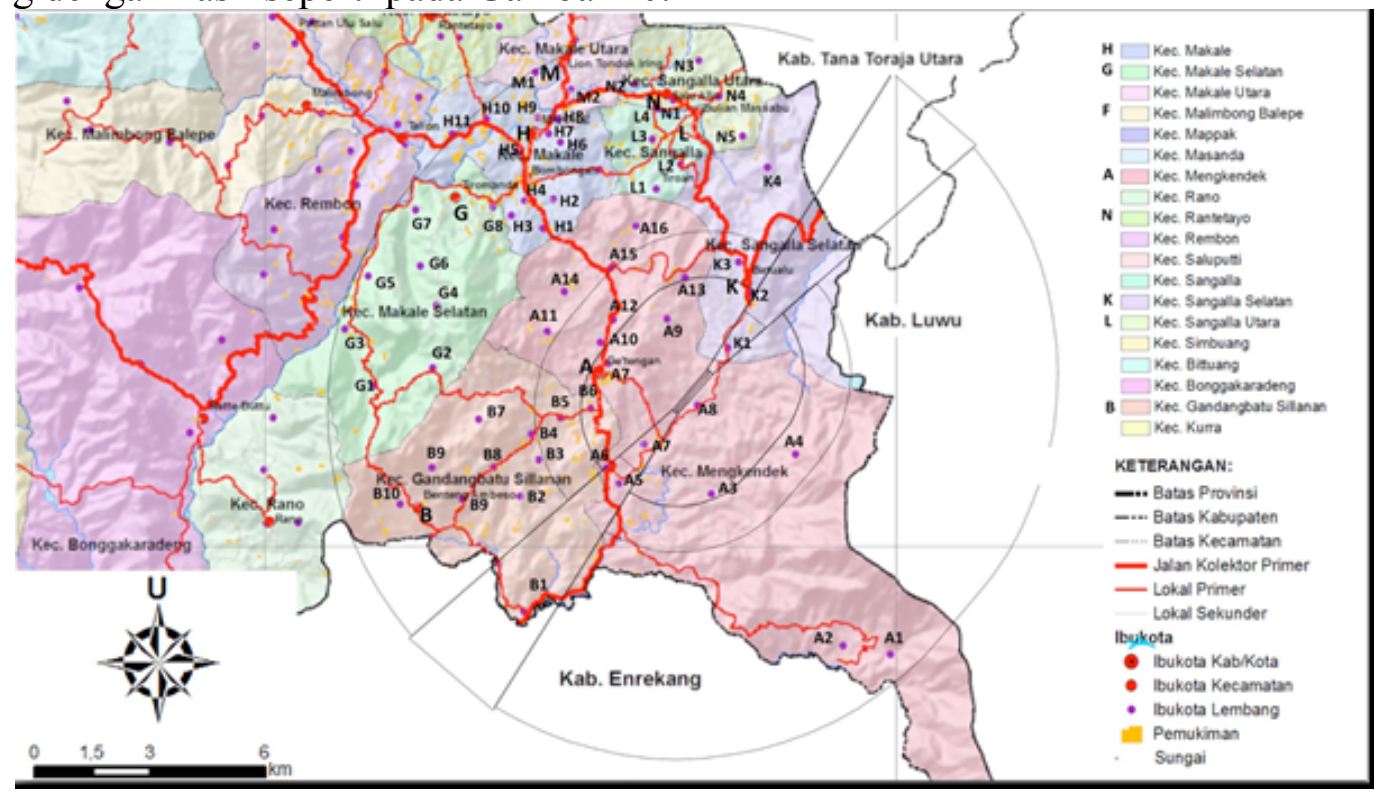

Gambar 10. Ibukota di Bawah KKOP dalam Peta Administrasi

Ada 8 Kecamatan yang keseluruhan bagiannya atau sebagian yang termasuk KKOP. Diidentifikasi Pusat Pelayanan yang terdiri dari 8 Ibukota Kecamatan dan 61 Ibukota Desa (Lembang), seperti pada Tabel 4 s.d 11.

Tabel 4. Pusat Pelayanan Kecamatan Mangkendek

\begin{tabular}{ccll}
\hline No. & Kode & \multicolumn{1}{c}{ Kelas } & Nama \\
\hline 1 & A & Ibukota Kecamatan & Gentengan \\
2 & A1 & Ibukota Lembang & \\
3 & A2 & Ibukota Lembang & \\
4 & A3 & Ibukota Lembang & \\
5 & A4 & Ibukota Lembang & \\
6 & A5 & Ibukota Lembang & \\
7 & A6 & Ibukota Lembang & \\
8 & A7 & Ibukota Lembang & \\
9 & A8 & Ibukota Lembang & \\
10 & A9 & Ibukota Lembang & \\
11 & A10 & Ibukota Lembang & \\
12 & A11 & Ibukota Lembang & \\
13 & A12 & Ibukota Lembang & \\
14 & A13 & Ibukota Lembang & \\
15 & A14 & Ibukota Lembang & \\
16 & A15 & Ibukota Lembang & \\
17 & A16 & Ibukota Lembang & \\
\hline
\end{tabular}

Tabel 5. Pusat Pelayanan Kecamatan Makale

\begin{tabular}{ccll}
\hline No. & Kode & \multicolumn{1}{c}{ Kelas } & Nama \\
1 & H & Ibukota Kecamatan & Bombonga \\
2 & H1 & Ibukota Lembang & \\
3 & H2 & Ibukota Lembang & \\
4 & H3 & Ibukota Lembang & \\
5 & H4 & Ibukota Lembang & \\
6 & H5 & Ibukota Lembang & \\
7 & H6 & Ibukota Lembang & \\
8 & H7 & Ibukota Lembang & \\
9 & H8 & Ibukota Lembang & \\
10 & H9 & Ibukota Lembang & \\
11 & H10 & Ibukota Lembang & \\
\hline
\end{tabular}


Tabel 6. Pusat Pelayanan Kecamatan Gandangbau Silanan

\begin{tabular}{cccc}
\hline No. & Kode & Kelas & Nama \\
\hline 1 & B & Ibukota Kecamatan & $\begin{array}{c}\text { Benteng } \\
\text { Ambeso }\end{array}$ \\
2 & B1 & Ibukota Lembang & \\
3 & B2 & Ibukota Lembang & \\
4 & B3 & Ibukota Lembang & \\
5 & B4 & Ibukota Lembang & \\
6 & B5 & Ibukota Lembang & \\
7 & B6 & Ibukota Lembang & \\
8 & B7 & Ibukota Lembang & \\
9 & B8 & Ibukota Lembang & \\
10 & B9 & Ibukota Lembang & \\
11 & B10 & Ibukota Lembang & \\
\hline
\end{tabular}

Tabel 8. Pusat Pelayanan Kecamatan Sanggala

\begin{tabular}{cclc}
\hline No. & Kode & \multicolumn{1}{c}{ Kelas } & Nama \\
\hline 1 & L & Ibukota Kecamatan & Tiromanda \\
2 & L1 & Ibukota Lembang & \\
3 & L2 & Ibukota Lembang & \\
4 & L3 & Ibukota Lembang & \\
\hline
\end{tabular}

Tabel 10. Pusat Pelayanan Kecamatan Sanggala Utara

\begin{tabular}{ccll}
\hline No. & Kode & \multicolumn{1}{c}{ Kelas } & Nama \\
\hline 1 & N & Ibukota & Salu Alo \\
& & Kecamatan & \\
2 & N1 & Ibukota Lembang & \\
3 & N2 & Ibukota Lembang & \\
4 & N3 & Ibukota Lembang & \\
5 & N4 & Ibukota Lembang & \\
6 & N5 & Ibukota Lembang & \\
\hline
\end{tabular}

Tabel 7. Pusat Pelayanan Kecamatan Makale Selatan

\begin{tabular}{ccll}
\hline No. & Kode & \multicolumn{1}{c}{ Kelas } & Nama \\
\hline 1 & G & Ibukota Kecamatan & Tiromanda \\
2 & G1 & Ibukota Lembang & \\
3 & G2 & Ibukota Lembang & \\
4 & G3 & Ibukota Lembang & \\
5 & G4 & Ibukota Lembang & \\
6 & G5 & Ibukota Lembang & \\
7 & G6 & Ibukota Lembang & \\
8 & G7 & Ibukota Lembang & \\
9 & G8 & Ibukota Lembang & \\
\hline
\end{tabular}

Tabel 9. Pusat Pelayanan Kecamatan Makale Utara

\begin{tabular}{ccll}
\hline No. & Kode & \multicolumn{1}{c}{ Kelas } & \multicolumn{1}{c}{ Nama } \\
\hline 1 & M & Ibukota Kecamatan & Lion Tondok \\
2 & M1 & Ibukota Lembang & Iring \\
3 & M2 & Ibukota Lembang & \\
\hline
\end{tabular}

Tabel 11. Pusat Pelayanan Kecamatan Sanggala Selatan

\begin{tabular}{cclc}
\hline No. & Kode & \multicolumn{1}{c}{ Kelas } & Nama \\
\hline 1 & K & Ibukota Kecamatan & Batualu \\
2 & K1 & Ibukota Lembang & \\
3 & K2 & Ibukota Lembang & \\
4 & K3 & Ibukota Lembang & \\
5 & K4 & Ibukota Lembang & \\
6 & K5 & Ibukota Lembang & \\
\hline
\end{tabular}

Mendata nama 61 Ibukota Lembang dan memeriksa kondisinya terkini akan dilakukan pada tahapan penelitian selanjutnya

\section{c. Klasifikasi Kemiringan Lereng}

Persyaratan kemiringan lereng yang yang termasuk urban area atau rural area, atau conservation area di bawah KKOP diperuntukan untuk Urban Area, Rural Area dan Conservartion Area pada Tabel 12. 
Tabel 12. Peruntukan Berdasarkan Kemiringan Lereng

\begin{tabular}{clcc}
\hline \multirow{2}{*}{ No. } & \multirow{2}{*}{ Peruntukan } & \multicolumn{2}{c}{ Kemiringan Lereng } \\
\cline { 2 - 4 } & Urban Area & $0--\& 8-15$ & $\mathrm{~d}^{0}$ \\
\hline 1 & Rural Area & $0-8,8-15,15-25, \& 25-40$ & $0-5,5-8,8-14 \& 14-22$ \\
2 & Conservation Area & $>40$ & $>22$ \\
\hline
\end{tabular}

Selain kemiringan lereng yang dinyatakan dengan presentase juga ditambahkan dengan derajad, agar terbayangkan kemiringan yang dimaksudkan. Diperoleh perletakan Pusat Pelayanan pada berbagai kemiringan lereng seperti pada Gambar 11.

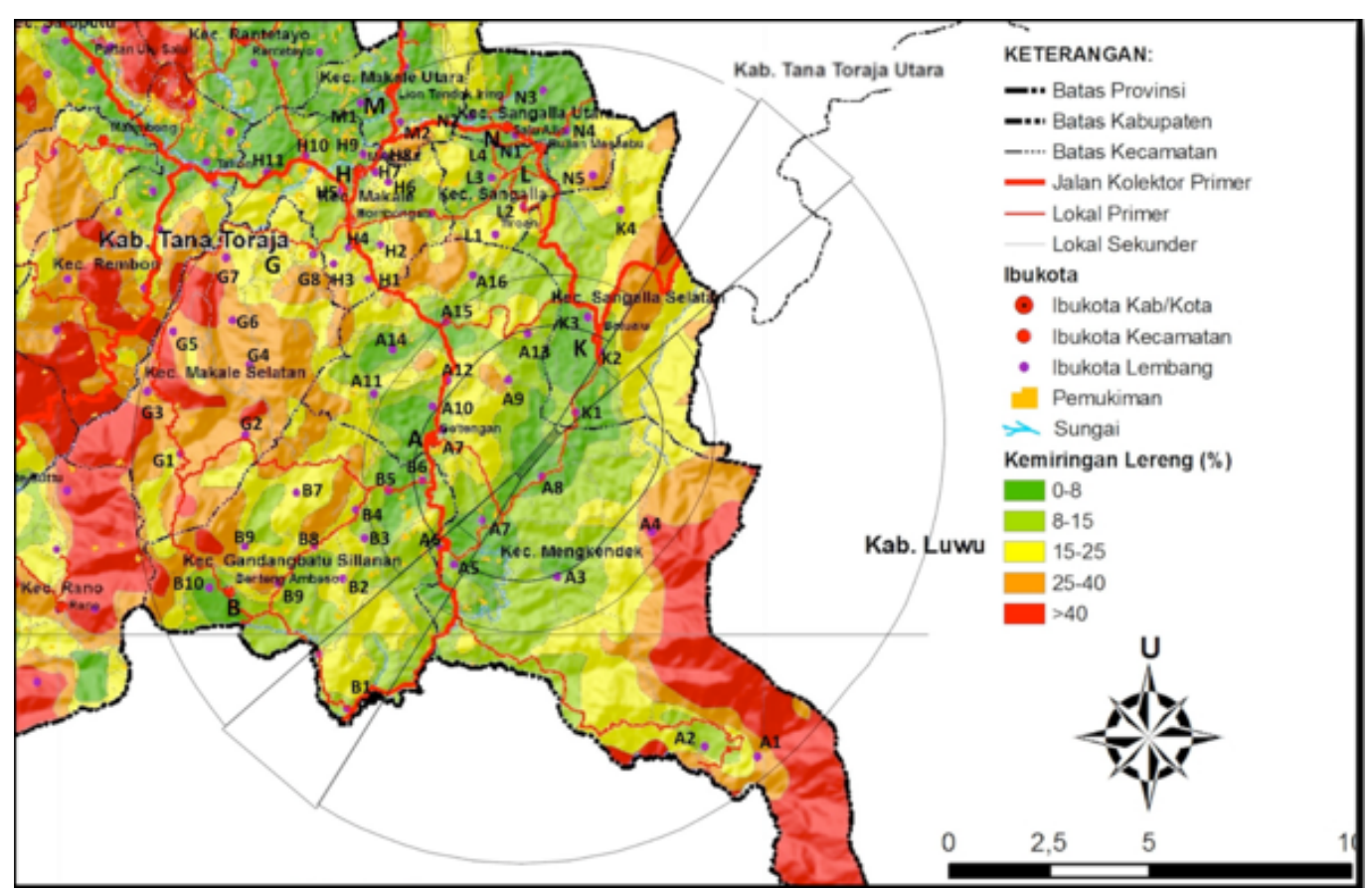

\section{Gambar 11. Pusat Pelayanan dalam Kemiringan Lereng}

Selain posisi pada Kemiringan Lereng, juga diperhatikan ketinggian Pusat Pelayanan dari muka air laut pada Peta Ketinggian (mdpl), seperti pada Gambar 12. 


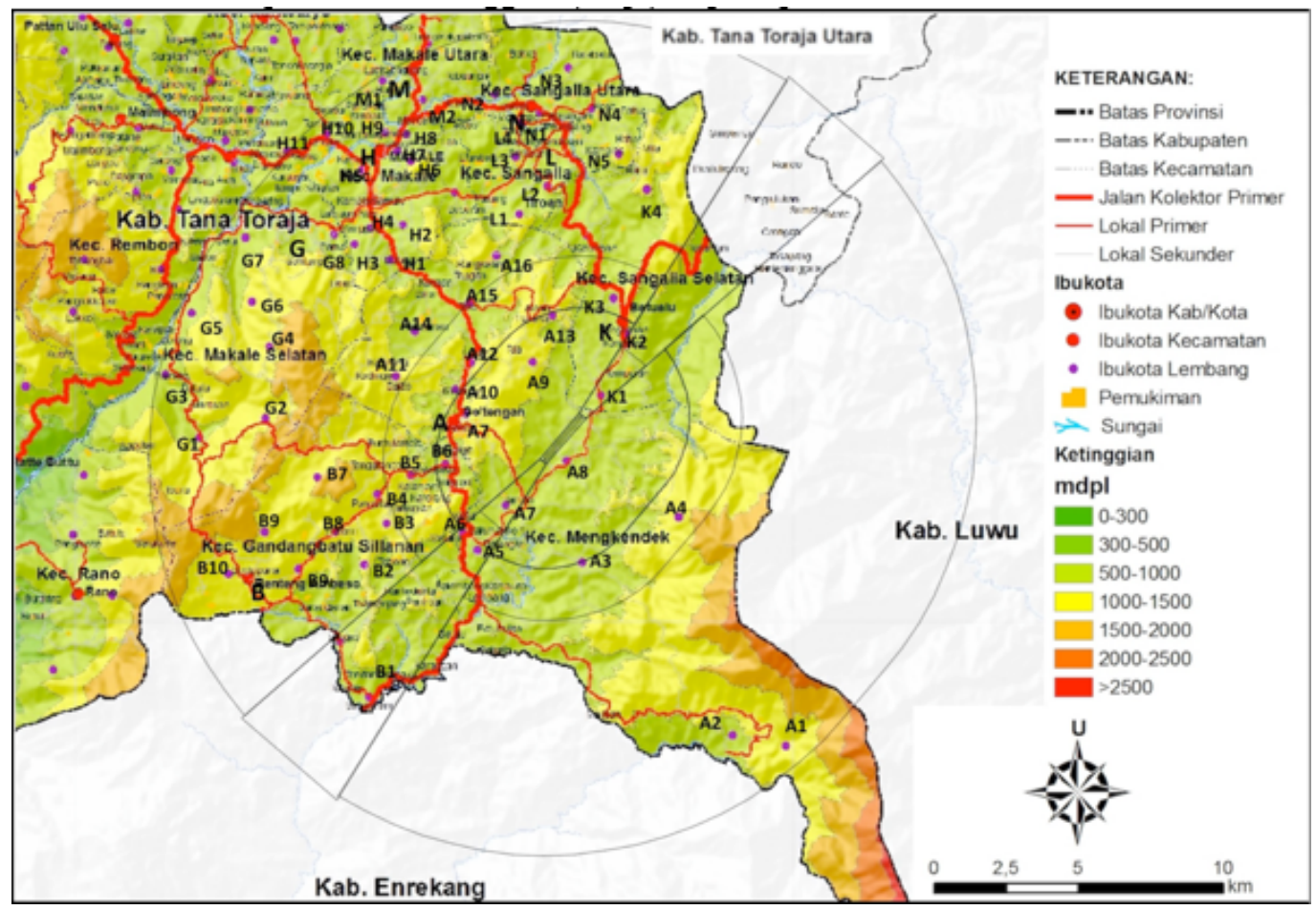

Gambar 12. Pusat Pelayanan dalam Ketinggian

Dengan memperhatikan penumpukan materi Peta Kemiringan Lereng, Peta Ketinggian, KKOP, Peta Administrasi, maka diperoleh penambahan penjelas pada tabel data Ibukota Kecamatan dan Ibukota Lembang, pada tahapan penelitian ini salah satu tabel yang mewakili data dasar, seperti pada Tabel 13.

Tabel 13. Kecamatan Gandangbatu Silanan

\begin{tabular}{cclcccc}
\hline No. & Kode & Kelas & Nama & $\begin{array}{c}\text { Kemiringan } \\
\text { Lereng (\%) }\end{array}$ & $\begin{array}{c}\text { Kemiringan } \\
\text { Lereng (d) }\end{array}$ & $\begin{array}{c}\text { Ketinggian } \\
(\mathbf{m d p l})\end{array}$ \\
\hline 1 & B & Ibukota Kecamatan & Benteng Ambeso & $0-8$ & $0-5$ & $1000-1500$ \\
2 & B1 & Ibukota Lembang & & $8-15$ & $5-8$ & $300-500$ \\
3 & B2 & Ibukota Lembang & & $15-25$ & $8-14$ & $1500-2000$ \\
4 & B3 & Ibukota Lembang & $8-15$ & $5-8$ & $1000-1500$ \\
5 & B4 & Ibukota Lembang & $15-25$ & $8-14$ & $1000-1500$ \\
6 & B5 & Ibukota Lembang & $0-8$ & $0-5$ & $1000-1500$ \\
7 & B6 & Ibukota Lembang & $0-8$ & $0-5$ & $500-1000$ \\
8 & B7 & Ibukota Lembang & $15-25$ & $8-14$ & $1500-2000$ \\
9 & B8 & Ibukota Lembang & $15-25$ & $8-14$ & $1000-1500$ \\
10 & B9 & Ibukota Lembang & & $15-25$ & $8-14$ & $1000-1500$ \\
11 & B10 & Ibukota Lembang & & $0-8$ & $0-5$ & $1000-1500$ \\
\hline
\end{tabular}

Ternyata ketinggian Ibukota pada ketinggian 1000 - 1500 mdpl sebanyak 7 unit, ketinggian 1500-2000 sebanyak 2 unit, ketinggian 500-1000 sebanyak 1 unit dan ketinggian 300-500 sebnyak 1 unit.

\section{d. Candidate Point untuk Ground Check berikut pembuatan WEB GIS}

Penentuan Candidate Point untuk Ground Check. Hasilnya merupakan salah satu materi rencana pembuatan aplikasi WEB GIS dilengkapi ketika penelitian ini diajukan ke 
RistekDikti.

\section{KESIMPULAN}

Materi tahapan penjajagan yang diperoleh ternyata hanya dua dari tiga materi tujuan, sebagai berikut:

1. Pendataan seluruh Ibukota di dalam KKOP Bandara Buntukunik.

2. Pendataan posisi Ibukota pada zonasi kelerengan yang termasuk urban area atau rural area, atau conservation area.

Penelitian berikutnya pada tahap kelayakan dengan materi sebagai berikut:

1. Penambahan atribut Zona Ketinggian Bangunan (zKTB).

2. Tipe Area dan Candidate Point (cPT_n) pada Tabel Ibukota.

3. Dan atribut lainnya.

\section{DAFTAR PUSTAKA}

[1]. Purwanto, E.H. 2017. Sistem Penunjang Keputusan Penerapan Kawasan Operasi Penerbangan Bandara Butukunik di Kabupaten Tana Toraja (Kasus: Materi Penetapan Tinggi Bangunan Tahap Penjajagan). Diperoleh dari : http://journal.uii.ac.id/index.php/Snati/arti cle/view/8458, 12 Nov 2017, Pk. 16:50 WIB

[2]. Purwanto, E.H., dan Karmilah, N., 2013. Penerapan Kawasan KKOP Berdasarkan Rencana Tata Bangunan dan Lingkungan di Kabupaten Tana Toraja, Jurnal Ilmiah Geomatika, V o.19, No.2, Cibinong, pp. 152.

[3]. Peraturan Menteri Pekerjaa Umum Nomor 06/PRT/M/2007 Tanggal 16 Maret 2007 Tentang Pedoman Umum Rencana Tata Banguan dan Lingkungan, p.25.

[4]. Peraturan Daerah Kabupaten Tana Toraja Nomor.12 Tahun 2011 Tentang Rencana Tata Ruang Wilayah Kabupaten Tana Toraja 2011-2030.

[5]. Lampiran PPRI No.8/2013, Peraturan Pemerintah Republik Indonesia Nomor. 8 Tahun 2013 Tentang Ketelitian Peta Rencana Tata Ruang, 1. Kerincian Kelas Unsur dan Simbolisasi Sistem Perkotaan.

[6]. Direktorat Jendral Reboisasi dan Rehabilitasi Lahan, Departemen Kehutanan, 1986, Pedoman Penyusunan Pola Rehabilitasi Lahan dan Konservasi Tanah 